\title{
An early Cenozoic perspective on greenhouse warming and carbon-cycle dynamics
}

\author{
James C. Zachos, Gerald R. Dickens \& Richard E. Zeebe
}

\begin{abstract}
Past episodes of greenhouse warming provide insight into the coupling of climate and the carbon cycle and thus may help to predict the consequences of unabated carbon emissions in the future.
\end{abstract}

By the year 2400, it is predicted that humans will have released about 5,000 gigatonnes of carbon $(\mathrm{Gt} \mathrm{C})$ to the atmosphere since the start of the industrial revolution if fossil-fuel emissions continue unabated and carbon-sequestration efforts remain at current levels ${ }^{1}$. This anthropogenic carbon input, predominantly carbon dioxide $\left(\mathrm{CO}_{2}\right)$, would eventually return to the geosphere through the deposition of calcium carbonate and organic matter ${ }^{2}$. Over the coming millennium, however, most would accumulate in the atmosphere and ocean. Even if only $60 \%$ accumulated in the atmosphere, the partial pressure of $\mathrm{CO}_{2}\left(p_{\mathrm{CO}_{2}}\right)$ would rise to 1,800 parts per million by volume (p.p.m.v.) (Fig. 1). A greater portion entering the ocean would decrease the atmospheric burden but with a consequence: significantly lower $\mathrm{pH}$ and carbonate ion concentrations of ocean surface layers ${ }^{1}$ (Fig. 1).

A marked increase in atmospheric $p_{\mathrm{CO}_{2}}$ would increase mean global temperature, thereby affecting atmospheric and oceanic circulation, precipitation patterns and intensity, the coverage and thickness of sea ice, and continental ice-sheet stability. However, forecasting the timing and magnitude of these responses is challenging because they can be nonlinear. Of particular concern are potential positive feedbacks that could amplify increases in the concentrations of greenhouse gases - water, $\mathrm{CO}_{2}$, methane and nitrous oxide $\left(\mathrm{N}_{2} \mathrm{O}\right)$ - effectively escalating climate sensitivity to initial anthropogenic carbon input ${ }^{3}$. For example, ocean surface warming and freshwater discharge at high latitudes could slow the exchange of shallow and deep water in the ocean, impeding both abiotic and biotic removal of anthropogenic carbon from the atmosphere. Potential negative feedbacks are also garnering great interest. As a possible counterbalance to decreased density of surface water on a warmer Earth, stronger zonal winds might increase ocean overturning (see page 286).

Observations of modern and Holocene (the past 10,000 years or so) climates have provided essential constraints for understanding climate dynamics and a baseline for predicting future responses to carbon input. But such observations can provide only limited insight into the response of climate to massive, rapid input of $\mathrm{CO}_{2}$. To evaluate climate theories more thoroughly, particularly with regard to feedbacks and climate sensitivity to $p_{\mathrm{CO}_{2}}$, it is desirable to study samples obtained when $\mathrm{CO}_{2}$ concentrations were high (approaching or exceeding 1,800 p.p.m.v.) and to make observations for intervals longer than those of ocean overturning and carbon cycling (more than 1,000 years $)^{4}$. Earth scientists have therefore turned increasingly to ancient time intervals, particularly those in which $p_{\mathrm{CO}_{2}}$ was much higher than now, in which $p_{\mathrm{CO}_{2}}$ changed rapidly, or both. Recent reconstructions of Earth's history have considerably improved our knowledge of known 'greenhouse' periods and have uncovered several previously unknown episodes of rapid emissions of greenhouse gases and abrupt warming.

\section{Cenozoic greenhouse climates}

The Cenozoic era, the last 65 million years of Earth's history, provides an ideal backdrop from which to understand relationships between carbon cycling and climate. In contrast to the present day, much of the early Cenozoic was characterized by noticeably higher concentrations of greenhouse gases, as well as a much warmer mean global temperature and poles with little or no ice ${ }^{5,6}$ (Fig. 2). The extreme case is the Early Eocene Climatic Optimum (EECO), 51-53 million years ago, when $p_{\mathrm{CO}_{2}}$ was high and global temperature reached a long-term maximum. Only over the past 34 million years have $\mathrm{CO}_{2}$ concentrations been low, temperatures relatively cool, and the poles glaciated. This longterm shift in Earth's climatic state resulted, in part, from differences in volcanic emissions, which were particularly high during parts of the Palaeocene and Eocene epochs (about 40-60 million years ago) but have diminished since then. Changes in chemical weathering of silicate rocks were also important ${ }^{7}$. On long timescales, this process sequesters $\mathrm{CO}_{2}$, preventing concentrations from rising too high or from falling too low. As the atmospheric $\mathrm{CO}_{2}$ concentration rises, temperature and precipitation increase and thereby enhance chemical weathering; as the concentration declines, temperature and precipitation decrease, slowing weathering. Whereas other processes (such as the oxidation and burial of organic carbon) change $\mathrm{CO}_{2}$ concentrations, the negative weathering feedback loop maintains Earth's climate within a habitable range over millions of years and longer ${ }^{7}$.

On shorter timescales, atmospheric $\mathrm{CO}_{2}$ concentration and temperature can change rapidly, as demonstrated by a series of events during the early Cenozoic known as hyperthermals. These were relatively brief intervals (less than a few tens of thousands of years) of extreme global warmth and massive carbon addition but with widely differing scales of forcing and response. During the most prominent and best-studied hyperthermal, the Palaeocene-Eocene Thermal Maximum (PETM; about 55 million years ago), the global temperature increased by more than $5^{\circ} \mathrm{C}$ in less than 10,000 years ${ }^{6}$ (Fig. 3). At about the same time, more than $2,000 \mathrm{Gt}$ Cas $\mathrm{CO}_{2}$ - comparable in magnitude to that which could occur over the coming centuries - entered the atmosphere and ocean.

Evidence for this carbon release is found in sedimentary records across the event. This includes a rapid and pronounced decrease in the ${ }^{13} \mathrm{C} /{ }^{12} \mathrm{C}$ ratio of carbonate and organic carbon across the globe (that is, a negative carbon isotope excursion) and a prominent drop in the carbonate content of marine sediment deposited at several thousands of metres water depth (that is, a deep-sea dissolution horizon) $)^{8}$. The first observation indicates injection into the atmosphere or ocean of a very large mass of ${ }^{13} \mathrm{C}$-depleted carbon, affecting the composition of the global carbon cycle. The second observation is a telltale signature of ocean acidification. The entire event lasted less than 170,000 years. Given the residence time of carbon (the average time a carbon atom spends in the ocean; about 100,000 years), this is consistent with a fast 


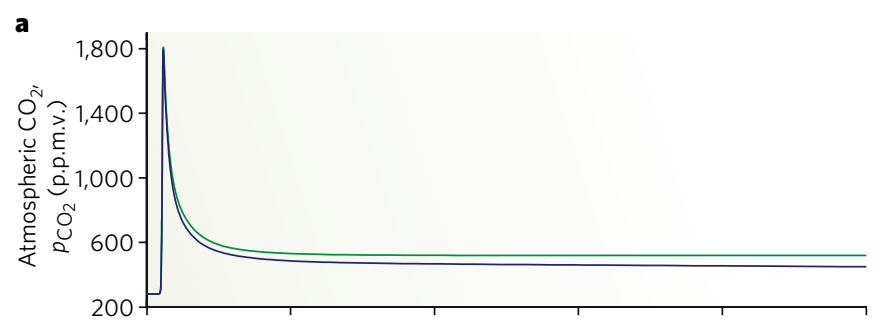

b

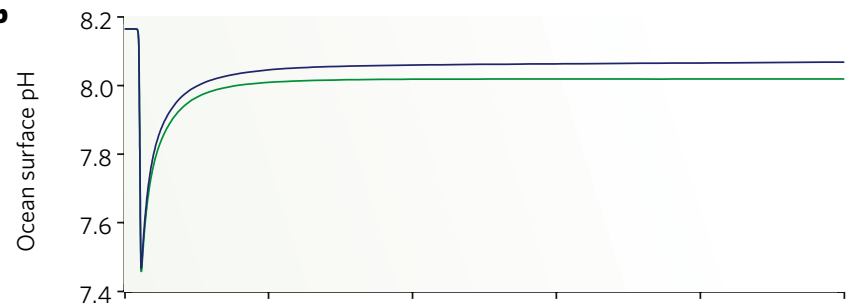

c

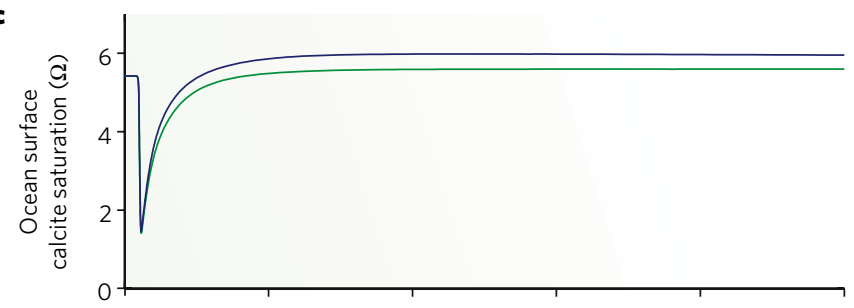

d

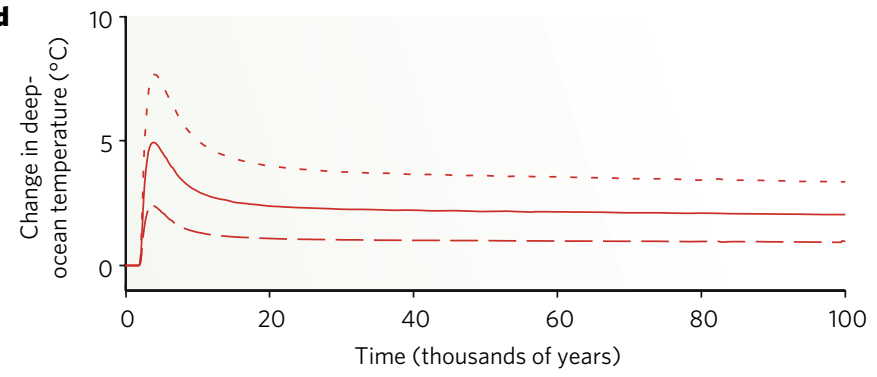

Figure 1 | Response to massive carbon input. A simulation of atmospheric $\mathrm{CO}_{2}(\mathbf{a})$, ocean surface $\mathrm{pH}(\mathbf{b})$, ocean surface calcite saturation (c) and deepocean temperature changes $(d)$ in response to the input of 5,000 Gt C of anthropogenic $\mathrm{CO}_{2}$ into the atmosphere, starting from pre-industrial $\mathrm{CO}_{2}$ levels (around the year 1860). These results were obtained with a carboncycle reservoir model coupled to a sediment model $^{7,19}$. Blue and green curves indicate, respectively, runs with and without a silicate-weathering feedback. Silicate-weathering feedback involves the chemical dissolution of siliconbearing rock on land, the primary permanent sink for $\mathrm{CO}_{2}$. Projected changes in deep-ocean temperature in d assume a homogeneous warming of the ocean with a time lag of 1,000 years relative to atmospheric $\mathrm{CO}_{2}$ (ref. 2) and the following temperature sensitivities to a doubling of $\mathrm{CO}_{2}$ concentration: shortdashed line, $4.5^{\circ} \mathrm{C}$; solid line, $3.0^{\circ} \mathrm{C}$; long-dashed line, $1.5^{\circ} \mathrm{C}$.

release and subsequently slower removal of carbon. Several other early Eocene hyperthermals have been documented recently ${ }^{9}$, including the Eocene Thermal Maximum 2 (Fig. 2). Although their features have not yet been fully established, the events are also characterized by negative carbon isotope excursions and deep-sea carbonate dissolution horizons, but are proportionally smaller than for the PETM.

The source or sources of massive carbon injections during early Cenozoic hyperthermals remain uncertain. Carbon might have come from deeply buried rocks, perhaps liberated as methane and $\mathrm{CO}_{2}$ during intrusive volcanism ${ }^{10}$. Alternatively, it could have come from Earth's surface as a positive feedback to initial warming. For example, a rise in deep-sea temperature might have triggered the decomposition of gas hydrates on continental margins, releasing substantial amounts of methane and fuelling additional warming ${ }^{11}$. Another such source is the oxidation of organic matter in terrestrial environments ${ }^{12,13}$. In general, methane is appealing as a major source of carbon because it can be markedly depleted in ${ }^{13} \mathrm{C}$ and because it rapidly oxidizes to $\mathrm{CO}_{2}$ in the atmosphere and ocean.

Irrespective of source, the hyperthermals occurred over sufficiently short durations that plate tectonic boundary conditions, although different from those of the present day, did not change substantially. In this regard, the hyperthermals provide a special opportunity to investigate aspects of Earth-system dynamics operating 100-10,000 years after a massive injection of carbon. Already, recent studies of the PETM seem to validate some forecasts about future first-order changes in climate: extreme ocean warming of more than $5^{\circ} \mathrm{C}$ extended to the North Pole; shifts in regional precipitation occurred, resulting in greater discharge from rivers at high latitudes and freshening of surface waters in the Arctic Ocean; and global ecosystems changed markedly, with major latitudinal and intercontinental migrations in terrestrial plants and mammals and with the sudden appearance of 'exotic' phytoplankton and zooplankton in open and coastal ocean environments (see refs 14 and 15 for reviews).

More importantly, the transient warming events show characteristics that are indicative of short-term positive feedbacks, which accelerated and magnified the effects of initial carbon injection before weathering and other negative feedbacks restored the global carbon cycle to a steady state. The most obvious characteristics are the timing and magnitude of various environmental signals. Stable-isotope and other records suggest that the abrupt and massive carbon input followed an interval of gradual warming and preceded an interval of decreased carbon uptake. Moreover, for the PETM, even the most conservative estimates of the mass of carbon released might require contributions from multiple sources.

\section{Opportunities and challenges}

The overall conditions and transient hyperthermals of the early Cenozoic represent an assortment of natural experiments that can help researchers to investigate the coupling of carbon cycling and climate over a range of timescales, and thus provide a means of testing theory. Two important opportunities are to evaluate the role of physical and biogeochemical feedbacks in amplifying or moderating increases in concentrations of greenhouse gases, and to investigate the basic sensitivity of climate to extreme changes in concentrations of greenhouse gases.

\section{Feedbacks}

The ocean is the primary carbon sink on moderate timescales (1001,000 years), so of the $5,000 \mathrm{Gt} C$ that humans could emit into the atmosphere (between the onset of the industrial revolution and the year 2400 ), the ocean would probably absorb roughly $70 \%$ after 1,000 years (Fig. 1). However, such carbon uptake depends on exchange between the thin and relatively warm surface layer that absorbs atmospheric $\mathrm{CO}_{2}$ and the much thicker and relatively cold deep-ocean reservoir that can store large amounts of carbon. As the small surface reservoir takes up $\mathrm{CO}_{2}$, its $\mathrm{pH}$ decreases ${ }^{1}$, slowing the additional absorption of $\mathrm{CO}_{2}$. To prevent the surface layer from becoming oversaturated, carbon must be shuttled quickly to the thermally isolated deep reservoir through advection (deep-ocean convection) or through the sinking of dead organisms (the biological pump). Unfortunately, rapid warming may compromise both processes. Warming and freshening of high-latitude surface water can slow the rate of convective overturning, and increased thermal stratification makes it more difficult for wind-driven mixing to return nutrients from the deep ocean to organisms in the photic zone (the upper $200 \mathrm{~m}$ or so of the water column, which is penetrated by sunlight, thereby allowing organisms to photosynthesize $)^{3}$. Although such a state cannot be sustained indefinitely, because diffusive processes would transfer heat to the deep ocean, it could accelerate the increase in atmospheric $\mathrm{CO}_{2}$ concentrations relative to steady-state conditions.

Is there any evidence of similar transient responses during past episodes of abrupt warming? High-resolution single-shell foraminiferal isotope records from the PETM suggest a delay of several thousand years in the propagation of the carbon isotope excursion from the surface ocean to the deep sea ${ }^{16}$, a pattern that could reflect a transient slowing of overturning circulation. If so, a combination of decreased 
ocean overturning and increased surface temperatures should have decreased the flow of dissolved oxygen to deep water. Several direct lines of evidence, such as laminated sediment in cores from the Caribbean and central Arctic regions, suggest that dissolved oxygen did indeed decrease across the PETM. Moreover, the PETM coincided with a major extinction of benthic foraminiferans, with widespread oxygen deficiency in the ocean as a possible cause ${ }^{17}$.

With such ocean conditions, greater preservation and burial of solid organic carbon in deep-sea sediments might be predicted, effectively countering the decreased carbon flux from surface waters. However, this has not been documented. Two largely unexplored processes involving the microbial decomposition of organic carbon, both functioning as additional positive feedbacks, might operate during times of massive carbon input and rapid warming. Carbonate dissolution in the deep ocean decreases sedimentation rates, exposing organic carbon at or near the sea floor for a longer duration, and warming of deep waters will accelerate overall microbial activity and the consumption of organic carbon. Future investigations might therefore focus specifically on the evidence for changes in ocean overturning, oxygen deficiency and the burial of organic carbon.

The positive feedbacks of greatest concern for understanding overall global warming may be those that could release hundreds to thousands of gigatonnes of carbon after initial warming ${ }^{1-13}$. The large masses of organic carbon stored in soils (for example, as peat) or sediments of shallow aquatic systems (for example, wetlands, bogs and swamps) represent a potential carbon input, should regions that were humid become drier. Rapid desiccation or fire could release carbon from these reservoirs at rates faster than carbon uptake by similar environments elsewhere. By contrast, regions that once were dry might emit methane as they become wetter ${ }^{18}$. Methane might also enter the ocean or atmosphere through the

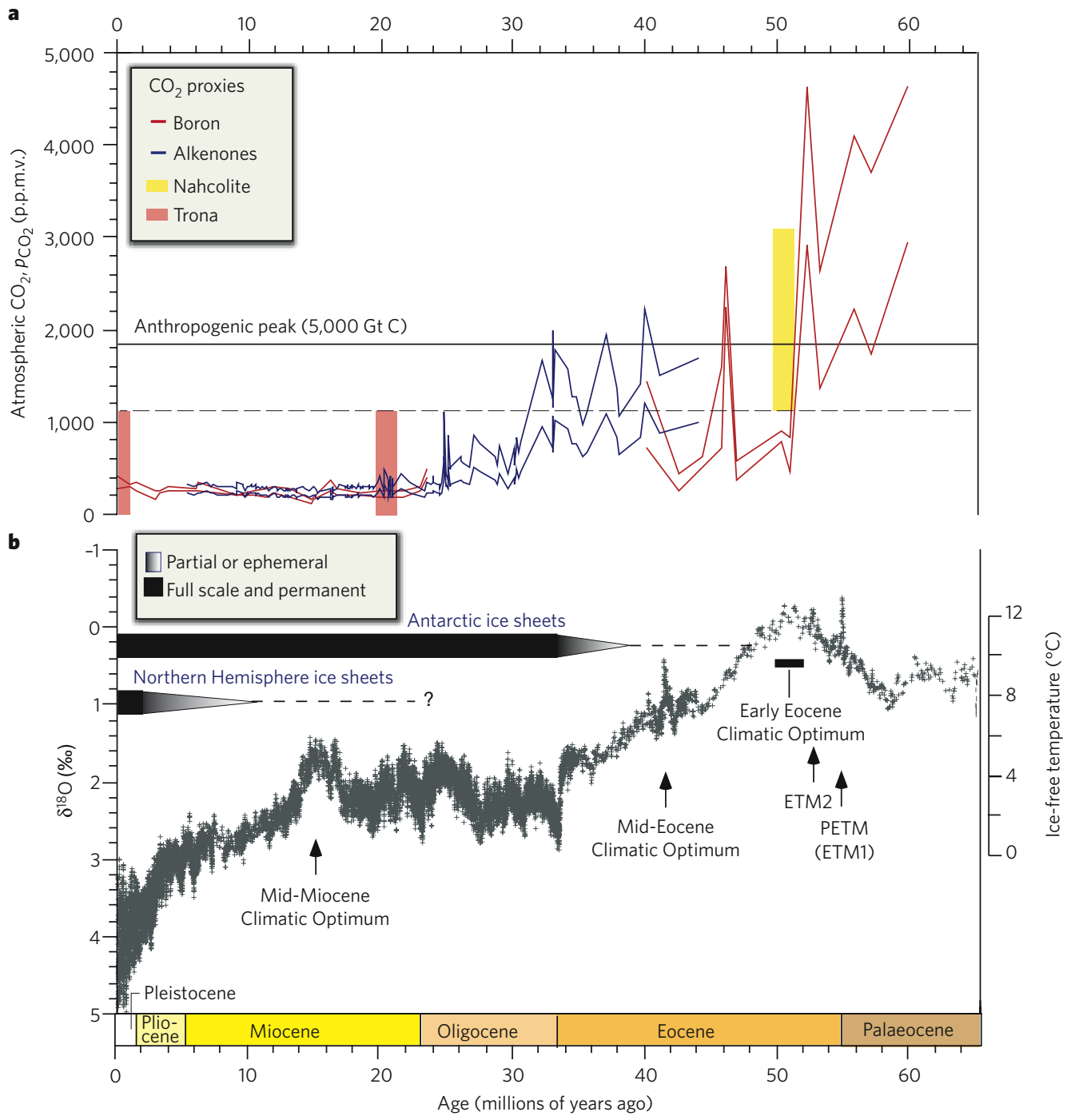

Figure 2 | Evolution of atmospheric $\mathrm{CO}_{2}$ levels and global climate over the past 65 million years. a, Cenozoic $p_{\mathrm{CO}_{2}}$ for the period 0 to 65 million years ago. Data are a compilation of marine (see ref. 5 for original sources) and lacustrine ${ }^{24}$ proxy records. The dashed horizontal line represents the maximum $p_{\mathrm{CO}_{2}}$ for the Neogene (Miocene to present) and the minimum $p_{\mathrm{CO}_{2}}$ for the early Eocene (1,125 p.p.m.v.), as constrained by calculations of equilibrium with $\mathrm{Na}-\mathrm{CO}_{3}$ mineral phases (vertical bars, where the length of the bars indicates the range of $p_{\mathrm{CO}_{2}}$ over which the mineral phases are stable) that are found in Neogene and early Eocene lacustrine deposits ${ }^{24}$. The vertical distance between the upper and lower coloured lines shows the range of uncertainty for the alkenone and boron proxies. $b$, The climate for the same period ( 0 to 65 million years ago). The climate curve is a stacked deep-sea benthic foraminiferal oxygen-isotope curve based on records from
Deep Sea Drilling Project and Ocean Drilling Program sites ${ }^{6}$, updated with high-resolution records for the interval spanning the middle Eocene to the middle Miocene $e^{25-27}$. Because the temporal and spatial distribution of records used in the stack are uneven, resulting in some biasing, the raw data were smoothed by using a five-point running mean. The $\delta^{18} \mathrm{O}$ temperature scale, on the right axis, was computed on the assumption of an ice-free ocean; it therefore applies only to the time preceding the onset of large-scale glaciation on Antarctica (about 35 million years ago). The figure clearly shows the 2-million-year-long Early Eocene Climatic Optimum and the more transient Mid-Eocene Climatic Optimum, and the very short-lived early Eocene hyperthermals such as the PETM (also known as Eocene Thermal Maximum 1, ETM1) and Eocene Thermal Maximum 2 (ETM2; also known as ELMO). \%o, parts per thousand. 

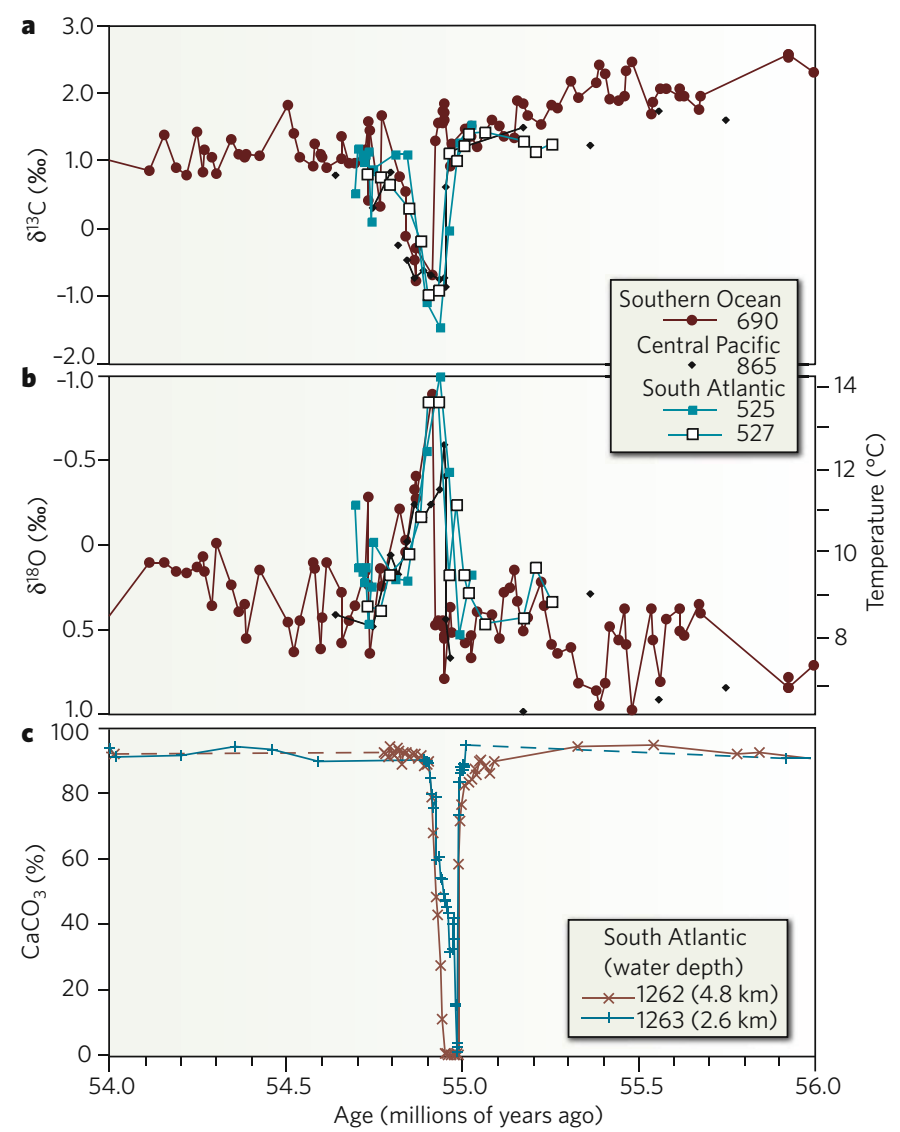

Figure 3 | Low-resolution marine stable-isotope records of the PETM and the carbon isotope excursion, together with the seafloor sediment $\mathrm{CaCO}_{3}$ record. The carbon isotope (a) and oxygen isotope (b) records are based on benthic foraminiferal records (see ref. 6 for original sources), and the $\mathrm{CaCO}_{3}$ records $(\mathbf{c})$ are from drill holes in the South Atlantic ${ }^{8}$. Panel b also shows inferred temperatures. Ocean drilling site locations are indicated in the keys. The decrease in sedimentary $\mathrm{CaCO}_{3}$ reflects increased dissolution and indicates a severe decrease in seawater $\mathrm{pH}$ (that is, ocean acidification). The base of the $\mathrm{CaCO}_{3}$ dissolution horizon is below the onset of the carbon isotope excursion because most of the carbonate dissolution involved uppermost Palaeocene sediments that were deposited before the event (chemical erosion). Panels $\mathbf{a}$ and $\mathbf{b}$ adapted, with permission, from ref. 6.

dissociation of gas hydrate in marine sediment. This feedback would probably take several thousands of years to initiate because heat must be propagated by ocean advection to water depths at which hydrates can form (more than $1 \mathrm{~km}$ in the early Cenozoic), and then by diffusion into sediments. However, the amount of methane that could be liberated is enormous, and after gas hydrate dissociation was initiated, the flux might proceed rapidly as overpressured pore waters triggered fluid expulsion or sediment slides on the sea floor ${ }^{11}$.

These potential carbon-cycle feedbacks for amplifying warmth are not fully understood. In fact, demonstrating that such feedbacks have operated in the past remains a major challenge. The abrupt negative carbon isotope excursions that mark the hyperthermals and attest to a massive input of isotopically depleted carbon cannot be used alone to identify the source, especially if more than one source existed. Records of geochemical or physical fingerprints, such as hopanoids from methanotrophs or charcoal from wildfires, would help ${ }^{18}$. Constraining the rate and mass of carbon released, for example by quantifying changes in ocean carbonate chemistry, is also essential for identifying sources ${ }^{19}$.

The PETM and other hyperthermals should also provide insight into the longer-term response of the carbon cycle to massive inputs of carbon, including the primary negative feedbacks that temporarily and permanently sequester carbon. Various simulations of the long-term fate of anthropogenic carbon emissions show consistent results. After the cessation of emissions, and a peak in atmospheric $p_{\mathrm{CO}_{2}}$, the ocean steadily absorbs much of the carbon, although with a decrease in $\mathrm{pH}$ and carbonate-ion concentration (Fig. 1). The carbonate-ion concentration is restored by dissolution of carbonate on the sea floor within several thousand years, but dissolved inorganic carbon and alkalinity remain high for tens of thousands of years afterwards. As a consequence, atmospheric $p_{\mathrm{CO}_{2}}$ does not return to pre-anthropogenic values but stabilizes at levels at least $50 \%$ higher than before the carbon injection (Fig. 1).

Marine-sediment records that span the PETM show features consistent with this pattern. The initial release of carbon, as represented by the carbon isotope excursion, is accompanied by widespread and significant dissolution of seafloor carbonate and a net deficit in deep-sea carbonate accumulation (Fig. 3). This is followed by an increase in carbonate accumulation at many locations, presumably reflecting a recovery of carbonate ion concentration ${ }^{8}$. Interestingly, carbonate accumulation during this recovery phase seems greater than before carbon injection, suggesting carbonate oversaturation. Although no detailed reconstructions of $\mathrm{P}_{\mathrm{CO}_{2}}$ are available for the PETM, surface temperatures remain warm for thousands of years after the input of carbon seems to cease. Thus, at first glance, observations of the PETM support the theory about the long-term fate of fossil-fuel $\mathrm{CO}_{2}$. The carbonate 'overshoot' represents a negative feedback, probably through enhanced silicate weathering and delivery of dissolved calcium and bicarbonate to the ocean. Gauging the sensitivity of this effect will enable the establishment of constraints on long-term forecasts for the carbon cycle following anthropogenic carbon emissions.

\section{Climate sensitivity}

Early Cenozoic climate has received considerable interest because the response of climate to a broad range of high atmospheric values of $p_{\mathrm{CO}_{2}}$ (probably 1,000 to more than 2,000 p.p.m.v.) can be examined. One feature common to all greenhouse periods, whether transient or long-lived, is exceptionally warm poles ${ }^{15}$. In the more extreme cases, the EECO and PETM, high-latitude temperatures were substantially higher than can be simulated by models without unreasonably high $p_{\mathrm{CO}_{2}}$ (refs 20,21). Somehow, models are not precisely simulating processes critical to poleward heat transport, albedo, or polar heat retention at higher greenhouse gas levels. Modified ocean heat transport has been investigated and found to be incapable of transporting heat fast enough to compensate for polar heat loss ${ }^{22}$. In contrast, polar stratospheric clouds, which might have been more extensive during the greenhouse intervals because of higher concentrations of methane in the atmosphere, seem to be very effective at trapping heat ${ }^{20}$. Similarly, non- $\mathrm{CO}_{2}$ greenhouse gases, which are usually neglected, may have had a major role. Recent theoretical and experimental studies indicate that, under high $p_{\mathrm{CO}_{2}}$, background concentrations of trace gases such as methane and $\mathrm{N}_{2} \mathrm{O}$ should be higher because of greater production under warmer and wetter conditions (that is, more extensive wetlands) and because of lower rates of oxidation in the atmosphere (resulting from lower emissions of volatile organic compounds by plants) ${ }^{21}$. Collectively, such physical and biochemical feedbacks would tend to enhance the sensitivity of climate to changes in $\mathrm{CO}_{2}$ and might explain the unusual polar warmth of the early Cenozoic.

Another prominent feature of the transient greenhouse episodes, specifically the PETM, are marked shifts in the distribution and intensity of precipitation, as inferred from fossil vegetation and other proxy data. Most regions, particularly in middle to high latitudes, experienced a shift towards wetter climates. However, the response on a regional scale was far more complex. For example, recent studies show that some regions, such as the western interior of North America, became drier at the onset of the PETM, whereas other regions, such as western Europe, experienced increased extreme precipitation events and massive flooding $^{23}$. These palaeo-observations imply a high degree of sensitivity in the hydrological cycle to extreme changes in $p_{\mathrm{CO}_{2}}$ and temperature. Additional documentation of precipitation changes for climatically sensitive regions during Eocene greenhouse episodes could prove useful for assessing how well models simulate extremes in climate. 


\section{Outlook for the future}

If fossil-fuel emissions continue unabated, in less than 300 years $p_{\mathrm{CO}_{2}}$ will reach about 1,800 p.p.m.v., a level not present on Earth for roughly 50 million years. Both the magnitude and the rate of rise complicate the goal of accurately forecasting how the climate will respond. Foremost among the challenges that must be overcome to achieve this goal is the development of a deeper understanding of the complex interactions that link the climate system with the biogeochemical cycles, specifically the role of positive and negative feedbacks. The occurrence of past greenhouse warming events provides one opportunity to test theory about the physical and biogeochemical interactions in rapidly shifting systems. There are of course limitations on which facets of theory and models can be tested given uncertainties in proxies and the limited spatial and temporal resolution of palaeorecords. Nevertheless, the past greenhouse events provide glimpses of the future. Until the most salient features of these events, for example the global patterns of carbonate deposition or the extreme polar warmth, can be replicated with dynamical models, forecasts of climate beyond the next century (that is, under extreme greenhouse gas levels) should be viewed with caution, and efforts to comprehend the underlying physics and biogeochemistry of the coupling between climate and the carbon cycle should be hastened. James C. Zachos is in the Department of Earth and Planetary Sciences, University of California at Santa Cruz, Santa Cruz, California 95060, USA. Gerald R. Dickens is in the Department of Earth Sciences, Rice University, Houston, Texas 77005, USA. Richard E. Zeebe is at the School of Ocean and Earth Science and Technology, University of Hawaii at Manoa, 1000 Pope Road, MSB 504, Honolulu, Hawaii 96822, USA.

1. Caldeira, K. \& Wicket, M. E. Anthropogenic carbon and ocean pH. Nature 425, 365-365 (2003).

2. Archer, D. Fate of fossil fuel $\mathrm{CO}_{2}$ in geologic time. J. Geophys. Res. Oceans $110, \mathrm{CO} 9 \mathrm{SO} 5$ doi:10.1029/2004JC002625 (2005).

3. Friedlingstein, P. et al. Climate-carbon cycle feedback analysis: Results from the (CMIP)M-4 model intercomparison. J. Clim. 19, 3337-3353 (2006).

4. Doney, S. C. \& Schimel, D. S. Carbon and climate system coupling on timescales from the Precambrian to the Anthropocene. Annu. Rev. Environ. Resources 32, 14.1-14.36 (2007).

5. Royer, D. L. $\mathrm{CO}_{2}$-forced climate thresholds during the Phanerozoic. Geochim. Cosmochim. Acta 70, 5665-5675 (2006).

6. Zachos, J., Pagani, M., Sloan, L., Thomas, E. \& Billups, K. Trends, rhythms, and aberrations in global climate 65 Ma to present. Science 292, 686-693 (2001).

7. Walker, J. C. G., Hays, P. B. \& Kasting, J. F. A negative feedback mechanism for the longterm stabilization of Earth's surface-temperature. J. Geophys. Res. Oceans Atmos. $\mathbf{8 6}$ 9776-9782 (1981).
8. Zachos, J. C. et al. Rapid acidification of the ocean during the Paleocene-Eocene Thermal Maximum. Science 308, 1611-1615 (2005).

9. Lourens, L. J. et al. Astronomical pacing of late Palaeocene to early Eocene global warming events. Nature 435, 1083-1087 (2005).

10. Svensen, $\mathrm{H}$. et al. Release of methane from a volcanic basin as a mechanism for initial Eocene global warming. Nature 429, 524-527 (2004).

11. Dickens, G. R. Rethinking the global carbon cycle with a large, dynamic and microbially mediated gas hydrate capacitor. Earth Planet. Sci. Lett. 213, 169-183 (2003).

12. Kurtz, A. C., Kump, L. R., Arthur, M. A., Zachos, J. C. \& Paytan, A. Early Cenozoic decoupling of the global carbon and sulfur cycles. Paleoceanography 18, 1090, doi:10.1029/ 2003PA000908 (2003).

13. Higgins, J. A. \& Schrag, D. P. Beyond methane: Towards a theory for the Paleocene-Eocene Thermal Maximum. Earth Planet. Sci. Lett. 245, 523-537 (2006).

14. Wing, S. L., Gingerich, P. D., Schmitz, B. \& Thomas, E. (eds). Causes and Consequences of Globally Warm Climates in the Early Paleocene (Geol. Soc. Am. Spec. Pap. 369, Boulder, Colorado, 2003)

15. Sluijs, A., Bowen, G. J., Brinkhuis, H., Lourens, L. J. \& Thomas, E. in Deep-Time Perspectives on Climate Change: Marrying the Signal from Computer Models and Biological Proxies (eds Williams, M. et al.) 323-349 (Geological Society of London, London, 2007).

16. Thomas, D. J., Zachos, J. C., Bralower, T. J., Thomas, E. \& Bohaty, S. Warming the fuel for the fire: Evidence for the thermal dissociation of methane hydrate during the PaleoceneEocene Thermal Maximum. Geology 30, 1067-1070 (2002).

17. Thomas, E. \& Shackleton, N. J. in Correlation of the Early Paleogene in Northwest Europe (eds Knox, R. W. O. B., Corfield, R. M. \& Dunay, R. E.) 401-441 (Geol. Soc. Lond. Spec. Publ. 101, London, 1996).

18. Pancost, R. D. et al. Increased terrestrial methane cycling at the Palaeocene-Eocene Thermal Maximum. Nature 449, 332-335 (2007).

19. Zeebe, R. E. \& Zachos, J. C. Reversed deep-sea carbonate ion basin gradient during Paleocene-Eocene Thermal Maximum. Paleoceanography 22, PA3201, doi:10.1029/ 2006PA001395 (2007).

20. Sloan, L. C. \& Pollard, D. Polar stratospheric clouds: A high latitude warming mechanism in an ancient greenhouse world. Geophys. Res. Lett. 25, 3517-3520 (1998).

21. Beerling, D. J., Hewitt, C. N., Pyle, J. A. \& Raven, J. A. Critical issues in trace gas biogeochemistry and global change. Phil. Trans. R. Soc. A 365, 1629-1642 (2007)

22. Huber, M. \& Sloan, L. C. Heat transport, deep waters, and thermal gradients: Coupled simulation of an Eocene greenhouse climate. Geophys. Res. Lett. 28, 3481-3484 (2001)

23. Schmitz, B. \& Pujalte, V. Abrupt increase in seasonal extreme precipitation at the Paleocene-Eocene boundary. Geology 35, 215-218 (2007).

24. Lowenstein, T. K. \& Demicco, R. V. Elevated Eocene atmospheric $\mathrm{CO}_{2}$ and its subsequent decline. Science 313, 1928-1928 (2006).

25. Billups, K., Channell, J. E. T. \& Zachos, J. Late Oligocene to early Miocene geochronology and paleoceanography from the subantarctic South Atlantic. Paleoceanography 17, U39-U49 (2002).

26. Bohaty, S. M. \& Zachos, J. C. Significant Southern Ocean warming event in the late middle Eocene. Geology 31, 1017-1020 (2003).

27. Palike, H. et al. The heartbeat of the Oligocene climate system. Science 314, 1894-1898 (2006).

Author Information Reprints and permissions information is available at npg.nature.com/reprints. Correspondence should be addressed to J.C.Z. and R.E.Z (jzachos@es.ucsc.edu; zeebe@hawaii.edu). 